\title{
Evaluación del efecto citotóxico de una resina dental a base de siloranos sobre fibroblastos L929
}

\author{
Evaluation of the cytotoxic effect of a \\ silorane-based dental resin on fibroblasts L929
}

Milena Guerrero F. ${ }^{1}$, Claudia X. Maya C. ${ }^{1}$, Maricela Vallejo L. ${ }^{1}$

Forma de citar: Guerrero Flórez M, Maya Cerón CX, Vallejo Labrada M. Evaluación del efecto citotóxico de una resina dental a base de siloranos sobre fibroblastos L929. Rev Univ Ind Santander Salud. 2016; 48(1): 71-80. DOI: http://dx.doi.org/10.18273/revsal.v48n1-2016008 (c) (1) ()

\section{RESUMEN}

Introducción: Las resinas dentales basadas en siloranos, son el resultado de la unión química de siloxanos y oxiranos. Dentro del proceso de evolución de las resinas, se han modificado sus formulaciones para optimizar sus propiedades físicas, mecánicas y estéticas. Sin embargo, aún presentan problemas como la contracción de polimerización, problemas alérgicos y toxicológicos. Objetivo: Determinar el potencial efecto citotóxico de las resinas a base de siloranos sobre la viabilidad celular en un cultivo de fibroblastos de la línea L929. Metodología: Se estudió la exposición de fibroblastos de ratón L929 a resinas dentales a base de siloranos Filtek p90 y metacrilatos Filtek p60 en tres tiempos de fotocurado durante 6 días. Se evaluó el efecto sobre la viabilidad celular mediante pruebas de exclusión vital, micrografías electrónicas y composición elemental de superficie ( $\mathrm{Mg}, \mathrm{Na}, \mathrm{K}$ y $\mathrm{Ca}$ ) por ESEM/EDAX. Resultados: La resina Filtek p90 mostró un mayor efecto citotóxico a tiempos de fotocurado prolongados (20 segundos o más) respecto a la resina Filtek p60. El efecto resultó más marcado para 20 segundos de fotocurado, ya que las concentraciones de $\mathrm{Ca}$ y $\mathrm{K}$ en la superficie celular fueron las más afectadas. Conclusiones: La resina dental Filtek p90 ejerce un efecto citotóxico relativamente bajo sobre las células de fibroblastos L929 $(\mathrm{p}<0.01)$. Su uso en la práctica odontológica se puede considerar bioseguro, pero un tiempo de fotocurado prolongado con la resina dental a base de siloranos puede afectar significativamente la viabilidad de los tejidos dentales.

Palabras clave: citotoxicidad, viabilidad celular, Fibroblastos, Microscopía electrónica de barrido.

\footnotetext{
Universidad Cooperativa de Colombia, Pasto, Colombia

Correspondencia: Maricela Vallejo Labrada. Dirección: Facultad de Odontología, Universidad Cooperativa de Colombia, calle 18 No.47-150, piso 1 bloque A. Correo Electrónico: maricela.vallejo@campusucc.edu.co. Teléfono: +057 2-7336706.
} 


\section{ABSTRACT}

Introduction: The resins dental based on siloranes, are the result of chemical bonding between siloxanes and oxiranes. In the process of evolution of the resins, they have changed their formulations to optimize their physical, mechanical and aesthetic properties. However have problems as polymerization shrinkage, allergic and toxicological problems. objective: determine the potential cytotoxic effect of siloranes based resins on cell viability in cultured fibroblast line L929. Methodology: The exposure of mouse L929 fibroblasts to commercial dental resins based on either, methacrylate Filtek P60 or silorane Filtek P90 for three curing times was assessed throughout 6 days. Its effect on the cell viability was determined by vital exclusion tests, electron micrographs and ionic composition ( $\mathrm{Mg}, \mathrm{Na}$, $\mathrm{K}$ and $\mathrm{Ca}$ ) by ESEM/EDAX. Results: The dental resin Filtek p90 displayed a higher cytotoxic effect for prolonged curing times (20 seconds or more) than the resin Filtek P60. Moreover, such an effect was stronger at 20 seconds of curing, as long as the concentration of $\mathrm{Ca}$ and $\mathrm{K}$ on the cell's surface were the more affected. Conclusions: The dental resin Filtek p90 exerts a relatively low cytotoxic effect on L929 fibroblast cells ( $p<0.01)$, and then, its use can be considered biologically safe in practical dentistry but a prolonged curing time of the silorane-based resin could significantly affect the viability of dental tissues.

Keywords: cytotoxicity, cell viability, Fibroblast, Scanning Electron Microscopy.

\section{INTRODUCCIÓN}

Las resinas dentales compuestas han evolucionado significativamente desde que se introdujeron los materiales en la industria odontológica ${ }^{1}$. Las resinas compuestas disponibles en el mercado tienen una base común en la polimerización de radicales libres de metacrilatos ${ }^{2}$. El alto volumen de contracción de resinas dentales basadas en acrilatos, se constituyó en la fuerza promotora para el desarrollo de materiales que contengan una matriz orgánica más ventajosa ${ }^{3}$. En el año 2007, la casa comercial $3 \mathrm{M}$, introdujo al mercado la resina dental Filtek p90 a base de siloranos, cuya molécula es un producto de la reacción de las moléculas de oxirano y siloxano. El sistema de siloranos tiene una menor contracción de polimerización respecto a las típicas resinas basadas en dimetacrilatos debido a la reacción de curado epóxido que involucra la apertura del anillo oxirano. Algunas ventajas del uso de resinas a base de siloranos son el menor deterioro y pérdida de color de los dientes, menor riesgo de fractura y como consecuencia menor posibilidad de infecciones y caries de los dientes restaurados. Además, estas resinas han demostrado buenas propiedades mecánicas 0,94-1,5\% en volumen y fuerza de contracción, comparable con las obtenidas con resinas a base de metacrilatos.

Las investigaciones más recientes en el área odontológica y de los materiales dentales se han concentrado especialmente en la matriz de relleno, las propiedades mecánicas y estéticas ${ }^{4}$. Algunas investigaciones han establecido que varios composites son liberados a partir de matrices polimerizadas de solventes orgánicos e inorgánicos, algunos de los cuales producen efectos adversos in vitro ${ }^{5}$. En este sentido, los composites contienen resinas oxirano/poliol que al ser fotocuradas con luz visible han mostrado una resistencia a la compresión comparable con aquellos materiales restaurativos de uso clínico basados en la química de los acrilatos $^{3}$. En un estudio clínico sobre color marginal, la resistencia de compresión ha demostrado ser inferior que la de un composite nanohíbrido ${ }^{1}$.

Por su parte, los estudios sobre compatibilidad biológica y citotoxicidad son una herramienta eficaz para garantizar el uso de biomateriales; los ensayos in vitro son útiles para evaluar los efectos de los biomateriales a nivel celular, no requieren animales de experimentación y tienen una buena relación costo/efectividad. Para determinar la compatibilidad y bioseguridad de un material se puede evaluar el comportamiento de células vivas en un ambiente controlado, analizando características del crecimiento celular, alteración de la membrana, replicación y transcripción de $\mathrm{ADN}$, síntesis de proteínas, hormonas y enzimas, metabolismo energético, transformación celular, mutagénesis y carcinogénesis.

Entre las pruebas más usadas para evaluar la permeabilidad celular y consecuente daño a nivel de membrana tras el uso de materiales dentales, se utiliza con frecuencia la prueba de exclusión vital con azul de tripan, la cual, se basa en la incapacidad de las células vivas parar incorporar dicho colorante, penetrando tan solo en las células muertas cuya membrana plasmática está alterada ${ }^{6}$. Para análisis de ultraestructura a nivel de superficie celular, se han utilizado metodologías tales como Microscopía electrónica de barrido (Scanning Electron Microscopy-SEM) y Microscopía Electrónica de Transmisión (Transmission Electron MicroscopyTEM) para obtener imágenes en tres dimensiones. SEM y la microscopia de fuerza atómica (Atomic Force 
Microscopy-AFM), también resultan complementarias en el análisis morfológico por imágenes.

En general, son muy pocas las investigaciones desarrolladas y reportadas en la literatura odontológica respecto a biocompatibilidad de resinas dentales a base de siloranos. Algunos hallazgos sobre efectos biológicos de oxiranos con base en mecanismos genéticos han sido contradictorios. Con la resina Cyracure TM UVR-6105 se ha reportado un test de Ames negativo en cepas de prueba de Salmonella TA1007. Existen evidencias experimentales de que algunos epóxidos reactivos son inductores más potentes de aberraciones cromosomales en células de organismos superiores. En contraste, se han encontrado mutaciones inducidas de genes por varios oxiranos en cepas de Salmonella TA100 y TA102, pero no se han detectado efectos con siloranos ${ }^{5}$.

Las resinas dentales tradicionales a base de metacrilatos, han demostrado tener un gran efecto citotóxico sobre una variedad de cultivos celulares; ésta razón junto con la importancia de garantizar el uso de materiales seguros, biocompatibles y con la mínima citotoxicidad para los tejidos que se encuentran en contacto directo con el material, permitieron buscar una mejor aproximación del efecto citotóxico que las nuevas resinas a base de siloranos puedan ejercer en células de fibroblastos y conllevó al desarrolló del presente estudio en condiciones de laboratorio donde se analizó la resina Filtek p90 sobre la viabilidad celular de fibroblastos de ratón de la línea celular L929.

\section{METODOLOGÍA}

Descripción. El presente estudio se desarrolló dentro de la línea de investigación en Biomateriales de la Facultad de Odontología de la Universidad Cooperativa de Colombia- Sede Pasto. En esta investigación se evaluó el efecto citotóxico de la resina dental a base de siloranos $3 \mathrm{M}^{\mathrm{TM}}$ Filtek ${ }^{\mathrm{TM}} \mathrm{P} 90$ in vitro. Para todos los análisis se realizó la exposición directa de fibroblastos de la línea celular L929 - ATCC CCL-1 a las resinas a base de siloranos Filtek p60 y Filtek p90 3M ${ }^{\mathrm{TM}}$. Se analizó la viabilidad a través de una prueba de exclusión vital, desarrollada en el laboratorio de Microbiología de la Universidad Cooperativa de Colombia - Pasto, así como también el daño morfológico y la alteración en la composición elemental de potasio $(\mathrm{K})$, magnesio $(\mathrm{Mg})$, sodio $(\mathrm{Na})$ y calcio $(\mathrm{Ca})$ sobre la superficie celular de fibroblastos L929 expuestos a resina mediante ESEM/EDAX. Ésta última prueba se llevó a cabo en el laboratorio de física del plasma de la Universidad Nacional de Colombia - Manizales.
Diseño experimental. El ensayo de citotoxicidad se realizó en placas de poliestireno de 24 pozos, donde se depositó un botón de resina Filtek p90 y Filtek p60 más un volumen de medio DMEN que contenía una cantidad inicial aproximada de 7,5 x $10^{5}$ células $/ \mathrm{ml}$ células de fibroblastos L929 ATCC CCL-1 por un tiempo de 6 días. Se evaluaron los factores experimentales: tiempo de fotocurado $(0,10$ y 20 segundos) y tipo de resina (p90 y p60). Las variables respuesta analizadas fueron el porcentaje de viabilidad y de composición elemental de $\mathrm{Ca}, \mathrm{Mg}$, Na y K. De todos los ensayos (E) se tomaron muestras cada 24 horas por triplicado para un total de 42 muestras analizadas en la prueba de viabilidad y 18 mediante EDAX.

Cultivo celular. El cultivo de fibroblastos L929 ATCCCCL1 se obtuvo de la colección de cultivos celulares de la Fundación in vitro, Cali-Valle. Las células de la línea L929 fueron cultivadas en condiciones estándar bajo los protocolos descritos por Takashima ${ }^{8}$. Todos los procedimientos de mantenimiento y cultivo se desarrollaron bajo estrictas condiciones de asepsia y bioseguridad.

Preparación de células de Fibroblastos L929. Para obtener la monocapa y la cantidad inicial de células a utilizar en los ensayos de citotoxicidad, a partir del cultivo celular previamente descrito se tomó una botella de cultivo de 24 horas con $50 \mathrm{ml}$ de medio con fibroblastos en confluencia total, se descartó la totalidad del medio de cultivo y se lavó la monocapa tres veces con $1.0 \mathrm{ml}$ de Buffer Salino Fosfato (PBS) estéril. Se hizo una tripsinización y se adicionó $1 \mathrm{ml}$ de medio de crecimiento consistente en medio DMEN (DulbeccoSigma) suplementado al $10 \%$ con Suero Fetal Bovino (SFB) (GIBCO). Para colectar las células, se trasvasó el contenido de la botella a un tubo de plástico (Biologix) de $15 \mathrm{ml}$ y se centrifugó a $2500 \mathrm{rpm} \times 5$ minutos. Al terminar este tiempo, se descartó el sobrenadante y se lavó el pellet 3 veces con PBS estéril, se adicionaron $5 \mathrm{ml}$ del medio de crecimiento, se llevó a incubación por 12 horas con atmósfera de $5 \%$ de $\mathrm{CO}_{2}$ a $37{ }^{\circ} \mathrm{C}$, posteriormente se realizó el conteo y ajuste de la densidad celular.

Preparación de la resina sobre placas de poliestireno. Se tomaron $0,15 \mathrm{~g}$ de resina Filtek p90 y Filtek p60 y se depositaron sobre un moldeador estéril en forma de botón con fondo plano y superficie convexa. Se polimerizaron con lámpara LED radii plus SDI con una intensidad mayor a $1000 \mathrm{mWatts} / \mathrm{cm}^{2}$, en el modo no rampa. Exposición de las células de fibroblastos L929 a las resinas. Se realizó en placas de poliestireno de 24 pozos, (Biologix). Una vez transferidos los botones de las resinas a cada pozo 
Salud Vol.48 No.1 Enero - Marzo de 2016

de las placas de cultivo se adicionó un volumen de 0,5 $\mathrm{ml}$ de cultivo ajustado a la densidad celular requerida y se completó con 1,5 ml de medio DMEN (Dulbecco-
Sigma) para un volumen de cultivo final de $2.0 \mathrm{ml}$ en cada pozo. La incubación se realizó por 6 días a $37^{\circ} \mathrm{C}$, $5 \%$ de $\mathrm{CO}_{2}$ y atmósfera humidificada. Tabla 1.

Tabla 1. Descripción ensayo de citotoxicidad de resinas Filtek p90 y p60 sobre fibroblastos L929.

\begin{tabular}{|c|c|c|c|c|c|}
\hline \multirow{2}{*}{ Código } & \multirow{2}{*}{ Tratamiento } & \multirow{2}{*}{$\begin{array}{l}\text { Tiempo de } \\
\text { incubación }\end{array}$} & \multicolumn{3}{|c|}{ Descripción de Tratamientos } \\
\hline & & & Tipo de resina & Tiempo de fotocurado & Células fibroblastos $/ \mathrm{ml}$ \\
\hline $\mathbf{E} 1$ & P90-T20 & \multirow{7}{*}{ día 1-día 6} & Filtek p90-Silorano & 20 segundos & \multirow{7}{*}{$7,5 \times 10^{5} \mathrm{clls} / \mathrm{ml}$} \\
\hline $\mathbf{E 2}$ & P90-T10 & & Filtek p90- Silorano & 10 segundos & \\
\hline $\mathbf{E 3}$ & P90-T0 & & Filtek p90- Silorano & Sin fotocurado & \\
\hline E4 & P60-T20 & & Filtek p60-Metacrilato & 20 segundos & \\
\hline E5 & P60-T10 & & Filtek p60-Metacrilato & 10 segundo & \\
\hline E6 & P60-T0 & & Filtek p60-Metacrilato & 0 segundos & \\
\hline E7 & L929 & & No & No & \\
\hline
\end{tabular}

Prueba de viabilidad por exclusión vital. Se tomaron muestras cada 24 horas por duplicado para un total de 42, se utilizó la coloración azul de tripan para determinar la densidad celular inicial y para la determinación del porcentaje de viabilidad ${ }^{9}$.A partir de una dilución 1:10 preparada con $1 \mu \mathrm{L}$ de la suspensión celular en $9 \mu \mathrm{L}$ de azul de tripán, se depositó en cámara de Neubauer y se observó con microscopio óptico OHAUS con el objetivo de 40, se realizó el conteo y se obtuvieron los datos de viabilidad en número de células $/ \mathrm{ml}$. Para calcular el porcentaje de viabilidad se utilizó la fórmula: $\%$ viabilidad $=(\#$ de células viables / \# total de células) x 100). Para estimar el porcentaje de mortalidad se utilizó la fórmula: \% mortalidad $=($ \# total de células muertas $/$ \# total de células $)$ x 100. Y el número total de células se obtuvo así: \# total células $=$ Promedio Células $\times 10$ x Vol x 10000, siendo 10 una constante; vol el volumen de $100 \mu \mathrm{L}$ depositado en la cámara de conteo y 10000, el factor de dilución).

Procesamiento de muestras para el ESEM/ EDAX. Se seleccionaron 18 muestras para su análisis, siguiendo los procedimientos y recomendaciones de preparación para ESEM descritos en Current Protocols ${ }^{10}$. Se analizaron muestras de resinas expuestas a las células directamente y muestras de células suspendidas en medio de cultivo líquido (no expuestas).

Fijación de material para EDAX. Se sumergieron portaobjetos de $0,7 \mathrm{~mm}$ de diámetro en ácido nítrico 5 M por 15 minutos a temperatura ambiente, en cámara extractora de aire. Se decantó el ácido nítrico y se lavó 10 veces con agua doblemente destilada. Se decantaron todos los remanentes de agua antes del lavado final. Se lavó cada portaobjetos dos veces con metanol y se colocaron en cajas de petri estériles.
Fijación de células con glutaraldehido para EDAX. A $0.15 \mathrm{ml}$ de suspensión celular se adicionaron 1.35 ml de glutaraldehido al $2.5 \%$ precalentado y se mezcló suavemente por inversión. Se sellaron los tubos con parafina y se incubaron por 2 horas a $37^{\circ} \mathrm{C}$, con agitación suave de $100 \mathrm{rpm}$ en agitador automático.

Se obtuvo el pellet de células por centrifugación durante $5 \mathrm{~min}$ a $2500 \mathrm{rpm}$ y temperatura ambiente. Se removió el sobrenadante completamente con una pipeta y resuspendió el pellet de células completamente en 1 $\mathrm{ml}$ de $\mathrm{PBS} \mathrm{pH}$ 7.4. Este procedimiento se repitió una vez más. Luego del segundo lavado, se removió el sobrenadante y se resuspendieron las células en $20 \mu \mathrm{L}$ de PBS pH 6.0.

Deshidratación y Secado de las muestras fijadas. A las muestras fijadas previamente se les realizó una serie de lavados con etanol al 25\%, 50\%, 75\%, 90\% y 100\%, incubando por 20 minutos a temperatura ambiente en cada grado de etanol. Las muestras se secaron en horno a $80^{\circ} \mathrm{C}$ durante 4 horas. Finalmente, se procedió a recortar con asa bisturí el fondo de cada pozo y se llevaron al análisis por ESEM/EDAX.

Análisis por ESEM/EDAX. Las muestras se llevaron al equipo de ESEM, al cual se aplicó vacío y enfriamiento con Nitrógeno líquido $-196^{\circ} \mathrm{C}$. Se tomaron micrografías en 40x, 180x y 1400x de aumento. Los espectros EDAX se obtuvieron tras realizar un barrido a nivel de superficie celular. Se tomaron 3 espectros por cada muestra, los resultados se obtuvieron en porcentaje de peso atómico $(\% \mathrm{At})$ y se graficaron para establecer tras este tiempo de exposición, las células mayormente afectadas. 
Evaluación del efecto citotóxico de una resina dental a base de siloranos sobre fibroblastos L929

Análisis de resultados. Con los resultados de la prueba de exclusión vital se calculó el porcentaje de viabilidad con el promedio de tres réplicas por tratamiento. Se obtuvo el número de células totales y se calculó el porcentaje de viabilidad y de mortalidad con base en el promedio de células vivas y células muertas respectivamente. Posteriormente, se aplicó una prueba $\mathrm{F}$ de normalidad al 95\% de significancia, análisis unidimensional y análisis de varianza. Los resultados de composición elemental obtenidos por EDAX se determinaron para cada elemento mediante la razón pico/fondo. El análisis del porcentaje de los elementos $\mathrm{Mg}$ y Ca se realizó por separado y el análisis de los elementos $\mathrm{K} / \mathrm{Na}$ se realizó utilizando el cociente de ambos. Para el análisis de estos resultados se tuvo en cuenta la función de transporte celular a través de la membrana en la cual participan estos elementos químicos.

\section{RESULTADOS}

Mediante el uso de la tinción de exclusión vital, se verificó la morfología compatible con las células de estudio. Se observaron células alargadas, fusiformes, móviles, sin coloración azul aparente, por lo cual se garantizó la viabilidad del cultivo para los ensayos posteriores.

Los resultados de la prueba de viabilidad obtenidos durante los 6 días del ensayo de exposición de las células de fibroblastos L929 a las resinas dentales Filtek p90 y Filtek p60 muestran que la mortalidad en todos los casos fue baja. Todos los datos fueron obtenidos por triplicado para cada tratamiento durante los 6 tiempos de seguimiento. Tabla 2.

Tabla 2. Resultados de la prueba de exclusión vital.

\begin{tabular}{|c|c|c|c|c|c|c|c|c|}
\hline Tratamiento & $\begin{array}{c}\text { Tiempo } \\
\text { TC }^{\mathbf{a}}\end{array}$ & $\begin{array}{c}\text { Promedio } \\
\text { células Vivas }\end{array}$ & $\begin{array}{c}\# \\
\text { células vivas }\end{array}$ & $\begin{array}{l}(\%) \\
\% V^{b}\end{array}$ & $\begin{array}{c}\text { Promedio } \\
\text { células muertas }\end{array}$ & $\begin{array}{c}\# \\
\text { células muertas }\end{array}$ & $\begin{array}{c}\text { (\%) } \\
\% \mathrm{Mc}\end{array}$ & $T C^{d}$ \\
\hline \multirow{6}{*}{ P90-T20 } & t0 & 74,5 & $7,45 \mathrm{E}^{+} 05$ & 100,0 & 0 & 0 & 0,00 & $7,45 \mathrm{E}^{+} 05$ \\
\hline & $\mathrm{t} 24$ & 205,5 & $2,06 \mathrm{E}^{+} 06$ & 97,4 & 5,5 & 55000 & 2,61 & $2,11 \mathrm{E}^{+} 06$ \\
\hline & $\mathrm{t} 48$ & 86,5 & $8,65 \mathrm{E}^{+} 05$ & 90,6 & 9 & 90000 & 9,42 & $9,55 \mathrm{E}^{+} 05$ \\
\hline & $\mathrm{t} 72$ & 123,5 & $1,24 \mathrm{E}^{+} 06$ & 90,8 & 12,5 & 125000 & 9,19 & $1,36 \mathrm{E}^{+} 06$ \\
\hline & t96 & 136 & $1,36 \mathrm{E}^{+} 06$ & 99,3 & 1 & 10000 & 0,73 & $1,37 \mathrm{E}^{+} 06$ \\
\hline & $\mathrm{t} 120$ & 90 & $9,00 \mathrm{E}^{+} 05$ & 97,8 & 2 & 20000 & 2,17 & $9,20 \mathrm{E}^{+} 05$ \\
\hline \multirow{6}{*}{ P90-T10 } & t0 & 74,5 & $7,45 \mathrm{E}^{+} 05$ & 100,0 & 0 & 0 & 0,00 & $7,45 \mathrm{E}^{+} 05$ \\
\hline & $\mathrm{t} 24$ & 589 & $5,89 \mathrm{E}^{+} 06$ & 98,1 & 11,5 & 115000 & 1,92 & $6,01 \mathrm{E}^{+} 06$ \\
\hline & $\mathrm{t} 48$ & 142,5 & $1,43 \mathrm{E}^{+} 06$ & 95,6 & 6,5 & 65000 & 4,36 & $1,49 \mathrm{E}^{+} 06$ \\
\hline & $\mathrm{t} 72$ & 220,5 & $2,21 \mathrm{E}^{+} 06$ & 95,9 & 9,5 & 95000 & 4,13 & $2,30 \mathrm{E}^{+} 06$ \\
\hline & $\mathrm{t} 96$ & 125 & $1,25 \mathrm{E}^{+} 06$ & 94,3 & 7,5 & 75000 & 5,66 & $1,33 \mathrm{E}^{+} 06$ \\
\hline & $\mathrm{t} 120$ & 96 & $9,60 \mathrm{E}^{+} 05$ & 93,2 & 7 & 70000 & 6,80 & $1,03 \mathrm{E}^{+} 06$ \\
\hline \multirow{6}{*}{ P90-T0 } & t0 & 74,5 & $7,45 \mathrm{E}^{+} 05$ & 100,0 & 0 & 0 & 0,00 & $7,45 \mathrm{E}^{+} 05$ \\
\hline & $\mathrm{t} 24$ & 300,5 & $3,01 \mathrm{E}^{+} 06$ & 99,3 & 2 & 20000 & 0,66 & $3,03 \mathrm{E}^{+} 06$ \\
\hline & $\mathrm{t} 48$ & 121 & $1,21 \mathrm{E}^{+} 06$ & 99,6 & 0,5 & 5000 & 0,41 & $1,22 \mathrm{E}^{+} 06$ \\
\hline & $\mathrm{t} 72$ & 110,5 & $1,11 \mathrm{E}^{+} 06$ & 99,1 & 1 & 10000 & 0,90 & $1,12 \mathrm{E}^{+} 06$ \\
\hline & t96 & 81 & $8,10 \mathrm{E}^{+} 05$ & 98,8 & 1 & 10000 & 1,22 & $8,20 \mathrm{E}^{+} 05$ \\
\hline & $\mathrm{t} 120$ & 123 & $1,23 \mathrm{E}^{+} 06$ & 99,2 & 1 & 10000 & 0,81 & $1,24 \mathrm{E}^{+} 06$ \\
\hline \multirow{7}{*}{ P60-T20 } & t0 & 74,5 & $7,45 \mathrm{E}^{+} 05$ & 100,0 & 0 & 0 & 0,00 & $7,45 \mathrm{E}^{+} 05$ \\
\hline & $\mathrm{t} 24$ & 210 & $2,10 \mathrm{E}^{+} 06$ & 98,8 & 2,5 & 25000 & 1,18 & $2,13 \mathrm{E}^{+} 06$ \\
\hline & $\mathrm{t} 48$ & 72 & $7,20 \mathrm{E}^{+} 05$ & 95,4 & 3,5 & 35000 & 4,64 & $7,55 \mathrm{E}^{+} 05$ \\
\hline & $\mathrm{t} 72$ & 86 & $8,60 \mathrm{E}^{+} 05$ & 95,0 & 4,5 & 45000 & 4,97 & $9,05 \mathrm{E}^{+} 05$ \\
\hline & t96 & 156 & $1,56 \mathrm{E}^{+} 06$ & 99,4 & 1 & 10000 & 0,64 & $1,57 \mathrm{E}^{+} 06$ \\
\hline & $\mathrm{t} 120$ & 164 & $1,64 \mathrm{E}^{+} 06$ & 99,4 & 1 & 10000 & 0,61 & $1,65 \mathrm{E}^{+} 06$ \\
\hline & t0 & 74,5 & $7,45 \mathrm{E}^{+} 05$ & 100,0 & 0 & 0 & 0,00 & $7,45 \mathrm{E}^{+} 05$ \\
\hline \multirow{5}{*}{ P60-T10 } & $\mathrm{t} 24$ & 582 & $5,82 \mathrm{E}^{+} 06$ & 99,0 & 6 & 60000 & 1,02 & $5,88 \mathrm{E}^{+} 06$ \\
\hline & $\mathrm{t} 48$ & 298 & $2,98 \mathrm{E}^{+} 06$ & 94,0 & 19 & 190000 & 5,99 & $3,17 \mathrm{E}^{+} 06$ \\
\hline & $\mathrm{t} 72$ & 165,5 & $1,66 \mathrm{E}^{+} 06$ & 96,2 & 6.5 & 65000 & 3,78 & $1,72 \mathrm{E}^{+} 06$ \\
\hline & $\mathrm{t} 96$ & 76 & $7,60 \mathrm{E}^{+} 05$ & 93,3 & 5.5 & 55000 & 6,75 & $8,15 \mathrm{E}^{+} 05$ \\
\hline & $\mathrm{t} 120$ & 149 & $1,49 \mathrm{E}^{+} 06$ & 96,8 & 5 & 50000 & 3,25 & $1,54 \mathrm{E}^{+} 06$ \\
\hline \multirow{6}{*}{ P60-T0 } & t0 & 74,5 & $7,45 \mathrm{E}^{+} 05$ & 100,0 & 0 & 0 & 0,00 & $7,45 \mathrm{E}^{+} 05$ \\
\hline & $\mathrm{t} 24$ & 232,5 & $2,33 \mathrm{E}^{+} 06$ & 98,3 & 4 & 40000 & 1,69 & $2,37 \mathrm{E}^{+} 06$ \\
\hline & $\mathrm{t} 48$ & 128,5 & $1,29 \mathrm{E}^{+} 06$ & 99,2 & 1 & 10000 & 0,77 & $1,30 \mathrm{E}^{+} 06$ \\
\hline & $\mathrm{t} 72$ & 41,5 & $4,15 \mathrm{E}^{+} 05$ & 97,6 & 1 & 10000 & 2,35 & $4,25 \mathrm{E}^{+} 05$ \\
\hline & t96 & 80,5 & $8,05 \mathrm{E}^{+} 05$ & 95,3 & 4 & 40000 & 4,73 & $8,45 \mathrm{E}^{+} 05$ \\
\hline & $\mathrm{t} 120$ & 168 & $1,68 \mathrm{E}^{+} 06$ & 98,8 & 2 & 20000 & 1,18 & $1,70 \mathrm{E}^{+} 06$ \\
\hline \multirow{6}{*}{ L929 } & t0 & 74,5 & $7,45 \mathrm{E}^{+} 05$ & 100,0 & 0 & 0 & 0,00 & $7,45 \mathrm{E}^{+} 05$ \\
\hline & $\mathrm{t} 24$ & 588 & $5,88 \mathrm{E}^{+} 06$ & 99,5 & 3 & 30000 & 0,51 & $5,91 \mathrm{E}^{+} 06$ \\
\hline & $\mathrm{t} 48$ & 204 & $2,04 \mathrm{E}^{+} 06$ & 97,6 & 5 & 50000 & 2,39 & $2,09 \mathrm{E}^{+} 06$ \\
\hline & $\mathrm{t} 72$ & 184 & $1,84 \mathrm{E}^{+} 06$ & 99,2 & 1,5 & 15000 & 0,81 & $1,86 \mathrm{E}^{+} 06$ \\
\hline & $\mathrm{t} 96$ & 146 & $1,46 \mathrm{E}^{+} 06$ & 97,3 & 4 & 40000 & 2,67 & $1,50 \mathrm{E}^{+} 06$ \\
\hline & $\mathrm{t} 120$ & 138 & $1,38 \mathrm{E}^{+} 06$ & 97,9 & 3 & 30000 & 2,13 & $1,41 \mathrm{E}^{+} 06$ \\
\hline
\end{tabular}

${ }^{a}$ Tiempo de cultivo en horas durante los 6 días de experimentación. ${ }^{b}$ Porcentaje viabilidad $=(\#$ de células viables / \# total de células $\left.) \times 100\right)$. ${ }^{~}$ Porcentaje de mortalidad $=(\#$ total de células muertas $/ \#$ total de células $) \times 100 .{ }^{\mathrm{d}} \mathrm{TC}$ Número Total Células $=($ Promedio Células $\times 10 \times$ Vol $\mathrm{x} 10000)$. 
El análisis unidimensional mostró todos los resultados de los siete ensayos (E1-E7), ajustados a una distribución normal dado que los valores de la asimetría tipificada y el coeficiente de Curtosis se encontraron dentro del rango esperado $(-2,+2)$. En el análisis de varianza para la comparación de medias, no se encontraron diferencias estadísticamente significativas en los resultados de viabilidad entre los ensayos E1-E7.

$\mathrm{Si}$ se comparan los resultados del ensayo E7 correspondiente a células de fibroblastos L929 sin exponer a resinas dentales, cuya prueba de viabilidad no presentó diferencias significativas respecto a los ensayos con células expuestas, se puede considerar un bajo efecto citotóxico de las resinas sobre las células estudiadas.

Al comparar la exposición de cada una de las resinas sobre la viabilidad celular, existe un efecto en promedio menor con p60 y con p90 en ausencia de fotocurado. Por otro lado, la combinación de la resina Filtek p90t20 evidencio un mayor efecto sobre la viabilidad celular respecto a los tratamientos $\mathrm{p} 90 \mathrm{t} 10$ y $\mathrm{p} 90 \mathrm{t} 0$. Figura 1

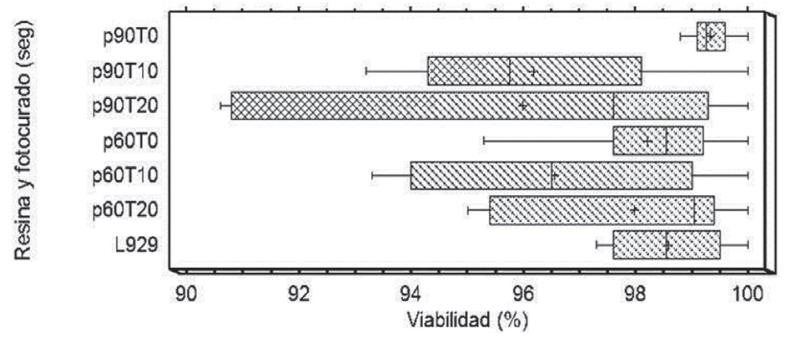

Figura 1. Efecto de la combinación entre tipo de resina y tiempo de fotocurado sobre la viabilidad celular (\%) de Fibroblastos L929.

El análisis de composición elemental por ESEM/ EDAX se obtuvo a partir de muestras de células fijadas en placas de vidrio. Para confirmar la adhesión de las células de fibroblastos L929 a la resina dental, se tomaron microfotografías de la resina con las células adheridas y se encontró que p90t20 fue el tratamiento que más efecto tuvo sobre la composición iónica analizada.

Los resultados de composición elemental de $\mathrm{Na}, \mathrm{K}, \mathrm{Mg}$ y Ca se obtuvieron en porcentaje de peso molecular (Wt) y peso atómico (At). Con los resultados de \%At se construyeron gráficas de composición de $\mathrm{Mg}, \mathrm{Ca}, \mathrm{K}$ y $\mathrm{Na}$, así como también del cociente de $\mathrm{K} / \mathrm{Na}$ con el fin de establecer la relación existente entre la variación de estos iones respecto al daño de la membrana celular evidenciado a través de la prueba de exclusión vital. A las 24 horas del ensayo la composición elemental de
Ca está significativamente baja en el tratamiento p90t20 respecto a los demás tratamientos. Figura 2A.

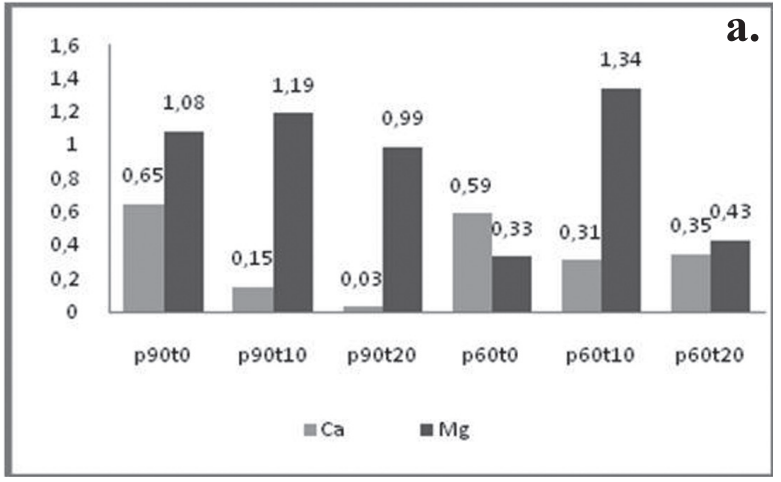

Figuras 2a . Composición elemental expresado en \%At, para los ensayos con la resina filtek p90 y p60 a las 24 horas del

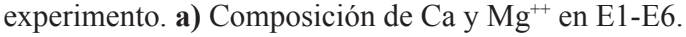

Es de tener en cuenta que la variación en la composición de Ca permite explicar el tipo de muerte celular, para este caso asociada a la exposición de las células a la resina a base de siloranos. Los iones de calcio tienen un papel significativo en una amplia variedad de actividades celulares, entre ellas la contracción muscular, división celular, secreción, fecundación, transmisión sináptica, metabolismo, transcripción y movimiento celular. La concentración de iones calcio en un compartimiento celular particular está bajo el control de la actividad reguladora de bombas de $\mathrm{Ca}$ y canales iónicos para $\mathrm{Ca}$ que se localizan dentro de las membranas que rodean el compartimiento ${ }^{11}$.

Respecto al ión $\mathrm{Mg}$, presenta una clara disminución en el tratamiento con la resina Filtek p60t0 a base de metacrilatos, mientras que en los tratamientos con la resina a base de siloranos se mantiene constante durante todo el experimento en los tres tiempos de fotocurado. Cabe mencionar que la disminución de $\mathrm{Mg}$ es afín con el descenso en la concentración de ATP, fenómeno que algunos autores lo han relacionado con procesos de muerte celular por necrosis ${ }^{12,13}$. Además es un elemento presente dentro de las células tanto en citoplasma como en membranas mitocondrial y plasmática $\mathrm{y}$ tiene un importante papel como cofactor de muchas enzimas implicadas en el metabolismo de las células, sin embargo, el análisis en este estudio se ve limitado debido a que el "screening" por EDAX se realizó solamente a nivel de la superficie de celular.

En el índice de $\mathrm{K} / \mathrm{Na}$, se puede evidenciar que con el tratamiento p90t0 se ve más afectado el equilibrio de estos dos iones, considerados importantes en el transporte a nivel de la membrana celular. Figura 2B 


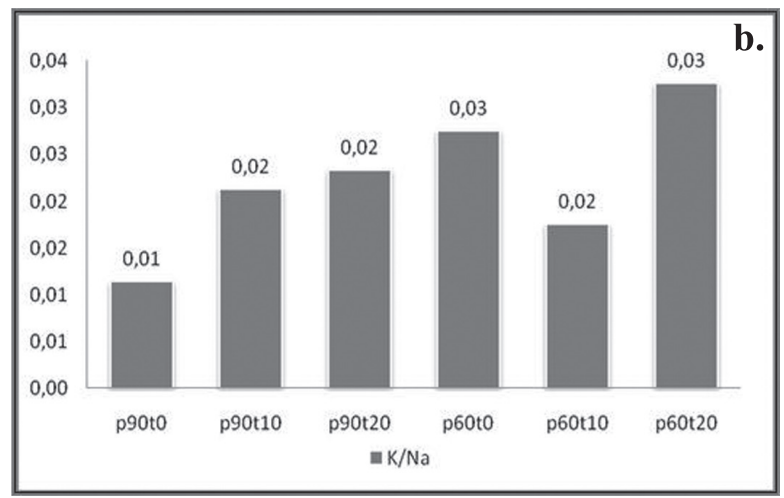

Figuras 2b. Composición elemental expresado en \%At, para los ensayos con la resina filtek p90 y p60 a las 24 horas del experimento. b) Índice $\mathrm{K} / \mathrm{Na}$ en E1-E6.

La concentración típica de $\mathrm{K}$ dentro de una célula de mamífero es cercana a $100 \mathrm{mM}$, mientas que fuera de la célula es solo de $5 \mathrm{mM}$. Por consiguiente, existe un intenso gradiente de concentración de $\mathrm{K}$ a través de la membrana plasmática que favorece la difusión de $\mathrm{K}$ hacia afuera de la célula. Los iones de $\mathrm{Na}$ también se distribuyen en concentración desigual a ambos lados de la membrana plasmática, pero el gradiente es opuesto respecto a la concentración de $\mathrm{K}$, ya que la concentración de $\mathrm{Na}$ es cercana a $150 \mathrm{mM}$ fuera de la célula y de 10-20 $\mathrm{mM}$ a nivel intracelular.

El índice de $\mathrm{K} / \mathrm{Na}$, fue significativamente más bajo en los tratamientos p90t0 y p60t10. El estudio del índice de $\mathrm{K} / \mathrm{Na}$ que según Roomans ${ }^{14}$, constituye uno de los criterios más sensibles y confiables de viabilidad celular, muestra para los tratamientos p90T0 y p60T10 la menor variación en la composición iónica, lo que corresponde con una menor pérdida de la viabilidad, a su vez, el desbalance entre estos dos elementos químicos, algunos autores lo han relacionado con procesos proapoptóticos celulares ${ }^{13}$.

El descenso en los niveles de $\mathrm{K}$ está asociado principalmente a procesos de muerte celular por apoptosis, proceso que en muchas células es normal y hasta necesario cuando cumplen con un ciclo de vida y funciones particulares, aunque también es un mecanismo para la eliminación de células anormales.

Con base en los anteriores resultados se realizó un seguimiento a los tratamientos que presentaron las mayores variaciones es decir, p90t0, p90t20, p60t10 y se construyeron gráficas para evaluar el efecto del tratamiento en dos tiempos de seguimiento. Se muestra que los iones $\mathrm{K}$ y $\mathrm{Mg}$, disminuyeron con el tiempo de exposición a la resina dental y tiempo de fotocurado de 20 segundos, y el ión Ca presenta un ligero incremento con el tiempo de exposición a la resina dental. Figura 3. Comportamiento diferente al observado para las células sin exposición, las cuales mantuvieron sus concentraciones iónicas estables durante todo el tiempo de experimentación.

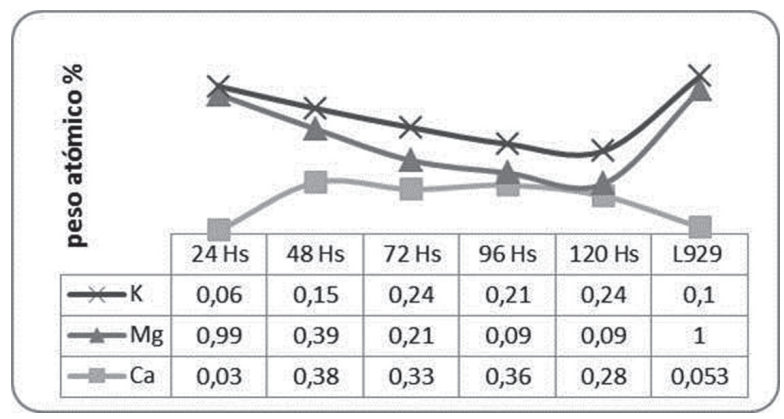

Figura 3. Composición elemental de $\mathrm{K}, \mathrm{Mg}$ y Ca durante a los 6 días de exposición de los fibroblastos L929 con el tratamiento p90t20, L929, corresponde a células sin tratamiento.

Estos resultados podrían dar indicios de eventos proapoptóticos que permitirían explicar el incrementado efecto citotóxico que tuvo la combinación p90t20, respecto a la células sin exponer a materiales dentales o aún expuestas pero con tiempos cortos de 10 segundos o incluso sin fotocurado.

Con microscopía electrónica de barrido en ambiente ESEM, los fibroblastos disminuyeron su tamaño y perdieron su morfología característica, esto puede deberse además de lo explicado anteriormente a una disminución en la capacidad para producir el colágeno.

\section{DISCUSIÓN}

La línea celular L929 (fibroblastos de ratón), ha sido ampliamente utilizada en estudios de biocompatibilidad de materiales odontológicos ${ }^{15,16}$ y es además la línea celular recomendada en las normas ISO 10993-5 para estudios in vitro ${ }^{17}$. El uso de cultivos celulares como parte de las pruebas recomendadas para evaluar el comportamiento biológico de los materiales al ser puestos en contacto con los tejidos humanos, se considera relativamente simple, reproducible, efectivo y de fácil manipulación ${ }^{18,19,20}$.

La lesión ocasionada por el efecto de biomateriales de uso odontológico a nivel celular, puede tener como objetivo los organelos celulares tales como las mitocondrias (responsables de la respiración celular), los ribosomas (síntesis proteica), el retículo endoplasmático (inducción enzimática y biodegradación) y las lesiones de núcleo (replicación del $\mathrm{ADN})^{21}$. 
Sin embargo, en este estudio se utilizó la prueba de exclusión vital con azul de tripán, un método colorimétrico que permite realizar una aproximación cuantitativa de sobrevivencia/viabilidad, en la cual la pérdida de viabilidad evidenciada en aquellas células que incorporan el colorante es un indicativo de daño a nivel de su membrana ${ }^{22}$. En este sentido, los valores de supervivencia celular en todos los grupos superaron el $90 \%$, estos resultados podrían explicarse en parte porque en este estudio el fotocurado de las resinas se realizó con lámpara de fotopolimerización de luz de emisión de diodos (LED).

En diferentes estudios realizados sobre fotopolimerizacion con lámpara LED han mostrado notables ventajas con respecto a las lámparas halógenas convencionales, lámparas de arco de plasma y lámparas de cuarzo de tungsteno, tales como una mejor calidad en la polimerización, una estructura interna del material más estable y una menor generación de calor, además de ventajas de tipo técnico como un mayor tiempo de vida útil (superior a 10.000 horas), mayor resistencia a los impactos, recalentamiento y vibración ${ }^{23,24,25,26}$.

El tiempo de exposición de las células a los materiales dentales, es un importante factor descrito en la literatura que influye sobre el grado de toxicidad de las resinas compuestas. En este sentido, en un estudio realizado por Ferracane y Condon ${ }^{27}$, encontraron que los efectos más tóxicos de las resinas hacia las células ocurren a las 24 horas de exposición, estos resultados se contradicen con los de otros autores en donde la máxima liberación de compuestos sin reaccionar ocurre después de este tiempo de exposición ${ }^{28}$. Con nuestros resultados, llama la atención que el efecto del tiempo de fotocurado es inverso entre Filtek p90 y Filtek p60. Es decir, aunque con Filtek p60 se afecta más la viabilidad sin fotocurado, en la medida que se aumenta el tiempo de fotocurado, disminuye ese efecto negativo sobre la viabilidad, mientras que para p90 es inverso, es decir, sin fotocurado se afecta la viabilidad celular en menor grado que con los 20 segundos de fotocurado.

Cuando el cultivo es expuesto a las resinas sin fotopolimerizar (p90T0 y p60T0), se observa que con la resina en base a metacrilatos Filtek p60, se presenta una mortalidad celular más alta, esto podría ser debido a que el mecanismo de polimerización de estas resinas es por radicales libres y se ha comprobado que una polimerización inadecuada o un bajo grado de conversión afecta la biocompatibilidad. Diferentes estudios comprueban que cuando el porcentaje de conversión de monómeros aumenta, la toxicidad celular disminuye ${ }^{29}$. Sin embargo, el porcentaje de monómeros sin reaccionar después de la polimerización inicial es más bajo en los nuevos materiales, aunque aún no existe una conversión total durante la polimerización, los efectos citotóxicos dependen de la permeabilidad dentinaria o grosor de la dentina remanente que son factores no controlables por parte del operador ${ }^{30,31,32}$.

Estudios in vitro han mostrado que la reacción de polimerización nunca es completa y los efectos adversos son debidos a la liberación de monómeros no polimerizados como el TEDGMA - BISGMA O UDMA. En otros estudios co-monómeros TEDGMA han sido identificados como los principales componentes que son liberados dentro de un medio acuoso causando citotoxicidad e inhibiendo el crecimiento celular en las primeras horas después de la polimerización inicial ${ }^{33,34}$. En cuanto a la resina Filtek p90 sin polimerizar se observa que la citotoxicidad es mínima, esta resina tiene un método de polimerización distinto, el estudio del método de polimerización por apertura de anillos y su relación con el nivel de celularidad de esta resina debería ser materia de interés ya que existen muy pocos estudios al respecto.

Los resultados evidenciaron diferencias sustanciales entre las dos resinas con relación al tiempo de fotocurado y el efecto de este sobre la viabilidad; se podría decir entonces, que la resina Filtek p90 requiere tiempos de fotocurado cortos y Filtek p60 requiere tiempos de fotocurado más largos, para mantener una mayor viabilidad celular.

La pérdida en los valores de calcio como la registrada en este experimento para el tratamiento p90t20, permiten inferir que a mayor tiempo de fotocurado mayor efecto sobre la viabilidad. Los iones de Ca pueden activar o inhibir varios sistemas enzimáticos y de transporte, cambiar la permeabilidad iónica de las membranas, inducir fusión de membranas o alterar la estructura y función del citoesqueleto.

Sin embargo, el Ca precipita estas reacciones junto con diversas proteínas de unión con calcio, como la calmodulina $(\mathrm{CaM})$, que se encuentra presente en células vegetales, animales, humanas y de microorganismos y cuyo papel es esencial en la función del Ca intracelular sobre todo cuando las células están expuestas a algún estímulo. El complejo $\mathrm{Ca}^{2+}-\mathrm{CaM}$, puede unirse con el sistema de transporte de $\mathrm{Ca}$ de la membrana plasmática, en cuyo caso, los niveles elevados de calcio en la membrana celular, activan el sistema encargado de liberar a la célula de cantidades 
excesivas del ión, lo que constituye un mecanismo de autoregulación para mantener las concentraciones intracelulares bajas de $\mathrm{Ca}$ tal como sucede en células en reposo o sin estímulos exógenos ${ }^{11}$.

Por otro lado, niveles bajos de $\mathrm{Ca}$ a nivel de la superficie celular podrían explicar una posible activación de la vía extrínseca de apoptosis en la cual varios estudios soportan la activación de oncogenes como $\mathrm{Bcl}-2^{35}$, lo cual permitiría explicar otro posible mecanismo de muerte celular desencadenado en los fibroblastos por la exposición a la resina dental.

\section{CONCLUSIONES}

El tratamiento p90t20 presenta el mayor efecto citotóxico respecto a los demás tratamientos, lo cual se evidenció con los resultados de la prueba de exclusión vital y se confirmó con los análisis de composición elemental por EDAX.

El análisis de composición iónica permitió evidenciar que las concentraciones de $\mathrm{K}$ y de Ca son principalmente afectadas tras la exposición de los fibroblastos a las dos resinas dentales, siendo afectados en mayor grado con la resina a base de metacrilatos (Filtek P60).

Nuestros resultados evidencian que las dos resinas dentales tienen efecto citotóxico ya que en ambos casos la viabilidad se ve afectada respecto al control L929 (Células sin exposición a resina dental), sin embargo, se garantiza su uso en la práctica odontológica ya que el grado de citotoxicidad evidenciado se ajusta al permitido para materiales de uso clínico.

Hay diferencias estadísticamente significativas entre las dos resinas con relación al tiempo de fotocurado y efecto de este sobre la viabilidad; se podría decir que la resina Filtek p90 requiere tiempos de fotocurado cortos y Filtek p60 requiere tiempos de fotocurado más largos, para garantizar un menor efecto citotóxico en ambos casos.

Los resultados del análisis de composición elemental podrían sugerir un efecto citotóxico mediado por la posible activación de un mecanismo apoptótico inducido por las resinas al utilizar la combinación tiempos de fotocurado y tiempos de exposición prolongados. Sin embargo, conclusiones al respecto requieren futuros estudios.

\section{CONFLICTO DE INTERÉS}

Los autores declaramos no tener conflicto de interés.

\section{REFERENCIAS}

1. Schneider LF, Cavalcante LM, Silikas N. Shrinkage stresses generated during resin-composite applications: A Review. J Dent Biomech. 2010; 131630. DOI: 10.4061/2010/131630.

2. Palasuk J, Platt JA, Cho SD, Levon JA, Brown DT, Hovijitra ST. Effect of surface treatments on microtensile bond strength of repaired aged silorane resin composite. Oper Dent. 2013; 38(1): 91-99. DOI: 10.2341/11-057-L.

3. Schweikl H, Schmalz G, Weinmann W. The induction of gene mutations and micronuclei by oxiranes and siloranes in mammalian cells in vitro. J Dent Res. 2004; 83(1): 17-21.

4. Lien W, Vandewalle KS. Physical properties of a new silorane-based restorative system. Dent Mater. 2010; 26(4): 337-344. DOI: 10.1016/j. dental.2009.12.004.

5. Schweikl H, Schmalz G, Weinmann W. Mutagenic activity of structurally related oxiranes and siloranes in Salmonella typhimurium. Mutat Res. 2002; 521(12): 19-27. DOI: 10.1016/S1383-5718(02)00207-3.

6. Schmalz G, Arenholt-Bindslev D. Determination of biocompatibility. Biocompatibility of dental materials. Germany. Edit springer S.A; 2009: p. 13-43.

7. Eick JD, KostoryzEL, Rozzi SM, Jacobs DW, Oxman $\mathrm{JD}$, Chappelow CC, et al. In vitro biocompatibility of oxirane/polyol dental composites with promising physical properties. Dent Mater. 2002; 18(5): 413-421. DOI: http://dx.doi.org/10.1016/s01095641(01)00071-9.

8. Bonifacino JS. Preparation and isolation of cells. Short protocols in cell biology: a compendium of methods from Current protocols in cell biology. 1 ra ed. Michigan: John Wiley \& Sons Inc; 2004: p. 2-5.

9. Strober W. Trypan blue exclusion test of cell viability. Curr Protoc Immunol. 2001; Appendix 3: Appendix 3B. DOI: 10.1002/0471142735.

10. Passey S, Pellegrin S, Mellor H. Scanning electron microscopy of cell surface morphology. Curr Protoc Cell Biol. 2007; Chapter 4:Unit4.17. DOI: 10.1002/0471143030.cb0417s37.

11. Hook SS, Means AR. Ca2+/CaM- dependent kinases: From activation to function. Annu Rev Pharmacol Toxicol. 2001; 41: 471-505. DOI: 10.1146/annurev.pharmtox.41.1.471.

12. Rodriguez IA. Efecto citotóxico de los sistemas adhesivos dentales. Estudio microscópico y microanalítico [Tesis Doctoral]. España: Universidad de Granada; 2005.

13. López G. Evaluación biológica de la toxicidad por 
2-hidroxietil metacrilato (HEMA) en fibroblastos gingivales humanos [Tesis doctoral]. España: Universidad de Granada; 2006.

14. Roomans GM. Pharmacological treatment of the ion transport effect in cystic fibrosis. Expert Opin Investig Drugs. 2001; 10(1): 1-19. DOI: 10.1517/13543784.10.1.1.

15. Jorge JH, Giampaolo ET, Pavarina AC. Citotoxicidade dos materiais dentários, revisão de Literatura. Revista da odontología de UNESP. 2004; 33(2): 65-68.

16. Ming Gene T, Wen Miin L, Tai Chin W, San Yue Ch. Evaluation of cytotoxicity of resin bonding materials toward human oral epithelial cells using three assay systems. J Dent Sci. 2009; 4(4): 178-186. DOI: http://dx.doi.org/10.1016/S1991-7902(09)60024-6.

17. International Standard Organization. ISO 109935:1992. Biological evaluation of medical devices part 5: tests for cytotoxicity: in vitro methods. 1992.

18. Vajrabhaya L, Pasasuk A, Harnirattisai C. Cytotoxicity evaluation of single component dentin bonding agents. Oper Dent. 2003; 28(4): 440-444.

19. Moharamzadeh K, Brook IM, Van Noort R. Biocompatibility of Resin-based Dental Materials. Materials. 2009; 2(2): 514-548. DOI: 10.3390/ ma2020514.

20. Wataha JC. Principles of biocompatibility for dental practitioners. J Prosthet Dentistry. 2001; 86(2): 203209. DOI: $10.1067 / \mathrm{mpr} .2001 .117056$.

21. Gisbert JA. Toxicología Especial. En: Villanueva Cañadas E. Medicina legal y toxicología. 5ta Edición. Barcelona: Masson S.A; 1998: p.10581073.

22. Ríos Hernández M, Cepero Cañas J, Davidenko N, Krael R, González Pérez A, Pérez K et al. Evaluación toxicológica in vitro de materiales poliméricos de restauración dental compuestos por BIS-GMA. Anuario Toxicología. 2001; 1(1): 65-72.

23. Ergün G, Eğilmez F, Üçtaşli MB, Yilmaz S. Effect of light curing type on cytotoxicity of dentinebonding agents. Int Endod J. 2007; 40(3): 216-222. DOI: $10.1111 / \mathrm{j} .1365-2591.2007 .01225 . x$.

24. Soares LE, Liporoni PC, Martin AA. The effect of soft-start polymerization by second generation LEDs on the degree of conversion of resin composite. Oper Dent. 2007; 32(2): 160-165. DOI: http:// dx.doi.org/10.2341/06-45.

25. Beriat NC, Ertan AA, Canay S, Gurpinar A, Onur
MA. Effect of different polymerization methods on the cytotoxicity of dental composites. Eur J Dent. 2010; 4(3): 287-292.

26. Ergun G, Egilmez F, Cekic-Nagas I. The cytotoxicity of resin composites cured with three light curing units at different curing distances. Med Oral Patol Oral Cir Bucal. 2011; 16(2): 252-259. DOI: 10.4317/ medoral.16.e252.

27. Ferracane JL, Condon JR. Rate of elution of leachable components from composite. Dent Mater. 1990; 6(4): 82-287. DOI: http://dx.doi.org/10.1016/ s0109-5641(05)80012-0.

28. Ferracane J-L. Resin composite-State of the art. Review. Dent Mater. 2011; 27(1): 29-38. DOI: 10.1016/j.dental.2010.10.020

29. Guiraldo RD, Consani S, Xediek Consani RL, Bittencourt Berger S, Batista Mendes W, Coelho Sinhoreti MA, et al. Comparison of Silorane and Metacrylate-Based composite resins on the curing light transmission. Braz Dent J. 2010; 21(6): 538-542.

30. Visvanathan A, Ilie N, Hicke R, Kunzelmann K. The influence of curing times and light curing methods on the polymerization shrinkage stress of a shrinkageoptimized composite with hybrid- type prepolymer fillers. Dent Mater. 2007; 23(7): 777-784. DOI: http: //dx.doi.org/10.1016/j.dental.2006.06.019.

31. Yap AJ, Seneviratne C. Influence of light energy density on effectiveness of composite cure. Oper Dent. 2001; 26(5): 460-466.

32. Nomoto R, Asada M, McCabe J, Hirano S. Light exposure required for optimum conversión of Light activated resin systems. Dent Mater. 2006; 22(12): 1135-1142. DOI: http: //dx.doi.org/10.1016/j. dental.2005.10.011

33. Ogunyinka A, Palin WM, Shortall AC, Marquis PM. Photoinitiation chemistry affects Light transmission and degree of conversion of curing experimental dental resin composites. Dent Mater. 2007: 23(7): 807-813. DOI: http: //dx.doi.org/10.1016/j. dental.2006.06.016.

34. Modena KC. Cytotoxicity and biocompatibility of direct and indirect pulp. J Appl Oral Sci. 2009; 17(6): 544-554. doi: 10.1590/S1678-77572009000600002.

35. Berridge MJ. Calcium signalling: Dynamics, homeostasis and remodeling. Nature Revs mol Cell Biol. 2003; 4(7): 517-529. DOI: 10.1038/ nrm 1155 . 